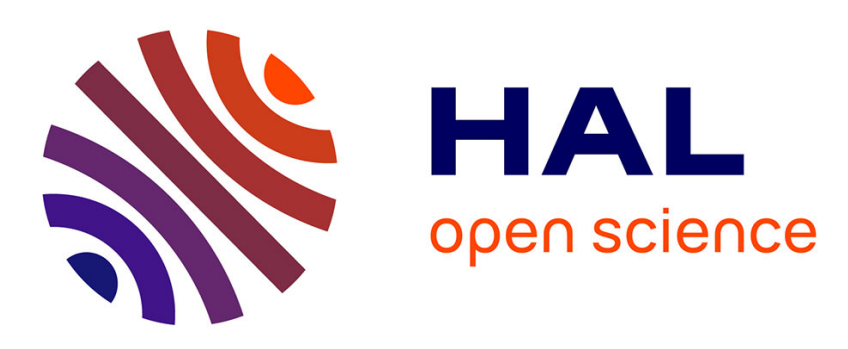

\title{
Spatial Integration of Natural Gas Markets: a Literature Review
}

Ekaterina Dukhanina, Olivier Massol

\section{To cite this version:}

Ekaterina Dukhanina, Olivier Massol. Spatial Integration of Natural Gas Markets: a Literature Review. Current Sustainable/Renewable Energy Reports, 2018, 5 (2), pp.129-137. 10.1007/s40518018-0107-7 . hal-01939648

\section{HAL Id: hal-01939648 \\ https://hal-ifp.archives-ouvertes.fr/hal-01939648}

Submitted on 29 Nov 2018

HAL is a multi-disciplinary open access archive for the deposit and dissemination of scientific research documents, whether they are published or not. The documents may come from teaching and research institutions in France or abroad, or from public or private research centers.
L'archive ouverte pluridisciplinaire HAL, est destinée au dépôt et à la diffusion de documents scientifiques de niveau recherche, publiés ou non, émanant des établissements d'enseignement et de recherche français ou étrangers, des laboratoires publics ou privés. 


\title{
Spatial integration of natural gas markets:
}

A literature review

\author{
Ekaterina DUKHANINA $^{\mathrm{a}, *} \quad$ Olivier MASSOL ${ }^{\mathrm{b}, \mathrm{c}, \mathrm{d}}$
}

\begin{abstract}
Purpose of Review: The purpose of this paper is to clarify the definition of an integrated market and to provide a commented overview of the different empirical methodologies that have been proposed to assess the degree of spatial integration of natural gas markets.

Recent Findings: In recent years, the methodologies assessing gas market integration have evolved from simple empirical works based solely on price data analyses to more complex ones based on the theoretical notion of spatial equilibrium capturing the effects of both price and non-price data.

Summary: A number of liberalization reforms have stimulated the emergence of spatially diverse markets for wholesale natural gas interconnected through spatial arbitrage, which plays a crucial role in the determination of local prices. In recent years, a vast and rapidly growing empirical literature has emerged to examine the degree of integration of these markets. A close examination of this literature has shown that only a handful of studies pay attention to the theoretical notion of market integration and account for the role played by trade flows, capacity constraints, and unit transaction costs.
\end{abstract}

Keywords Spatial integration; Law of one price; Integration of gas markets; Natural gas markets; Market integration; Price convergence

a Centre for Industrial Economics, CERNA, Mines ParisTech, 60 bd Saint-Michel, 75272 Paris Cedex 06, France.

b IFP Énergies Nouvelles, 1-4 av. de Bois Préau, F-92852 Rueil-Malmaison, France.

c Center for Economics and Management, IFP School, 228-232 av. Napoléon Bonaparte, F-92852 Rueil-Malmaison, France.

d Department of Economics, City University of London, Northampton Square, London EC1V 0HB, UK.

* Corresponding author. E-mail address: ekaterina.dukhanina@mines-paristech.fr 


\section{1 - Introduction}

A series of concomitant factors have deeply transformed the organization and functioning of the natural gas industry in recent decades. A non-exhaustive list includes: the deployment of new pipeline and liquefied natural gas (LNG) infrastructures that are supporting the development of natural gas trade; the major restructuring reforms conducted in the US and in Europe aimed at the liberalization of the gas industry; and the declining use of long-term contracts based on traditional, oil-indexed, pricing schemes. Sweeping regulatory reforms have stimulated the emergence of spatially localized spot markets for wholesale natural gas that are interconnected throughout a pipeline network or via LNG routes. From a collection of segmented markets mainly supplied by neighboring producers, we now observe a collection of interdependent and tightly linked regional markets.

As the spatial arbitrage performed between these markets is now playing a crucial role in the determination of local prices, a number of questions are emerging. Are we facing a globally integrated market for natural gas or a set of geographically segmented ones? Does infrastructure utilization matter for understanding how the prices are formed? Does spatial arbitrage contribute to the integration of natural gas markets? Given the importance of having an integrated gas market, ${ }^{1}$ as it opens more opportunities for producers, provides cost efficient gas for consumers and, from a public policy perspective, reinforces the security of supply, it is worth knowing how the degree of market integration can be measured. These questions have motivated a vast and growing empirical literature and the purpose of this paper is to provide a commented overview of these studies.

The analysis of the related literature provides us with some insights into spatial integration. A host of empirical studies document an increasing degree of integration among regional gas markets over time and suggest that regulatory interventions have played an important role in this process. However, it is too early to speak about a unique integrated world gas market. We find that the methodologies assessing the degree of market integration have evolved from simple static empirical works, based solely on price data analyses, to more complex ones, paying attention to market evolution, arbitrage opportunities, transaction costs, trade flows, and capacity constraints. It should be noted that even if recent works capture the effects of both price and non-price data, only a handful of studies are consistent with the theoretical conditions for spatial equilibrium.

The remainder of the paper is organized as follows. In section 2, we review the definition of an integrated market. Section 3 presents an overview of the methodologies that have been applied to assess the degree of spatial integration between natural gas markets. The merits of these approaches are discussed in section 4. The final section concludes.

\section{2 - Definition}

Before talking about the specifics of empirical studies on the integration of natural gas markets, we briefly review its theoretical foundations using a broader historical perspective. Our aim is to present the intellectual roots of the issues affecting contemporary empirical studies of natural gas markets. Hence, it

\footnotetext{
${ }^{1}$ See the discussions about a competitive European gas market (ACER, 2015), the needs for an "integrated energy market" in Europe (Energy Union package, 2015) and "the integration of the electricity and the gas markets at the European level” (Energy Union: Key Decisions for the Realization of a Fully Integrated Energy Market, 2016).
} 
should not be viewed as an exhaustive epistemological discussion on the notion of spatial market integration.

Historically, Cournot (1838, p.55) first defines an economic market ${ }^{2}$ as follows: “(...) economists understand by the term market not a particular place where sales and purchases are carried out but a whole territory in which parties are in such free intercourse with one another that prices of the same goods are levelled out easily and promptly (...).” That early definition calls for two remarks that are relevant for the present discussion. First, it explicitly refers to a dynamic notion of price convergence that should be "easy" and "prompt." As we shall see in the sequel, this idea provides the intellectual cornerstone for several time-series approaches that operationalize the concept of price convergence. Second, it is worth noting that in Cournot's definition the price of the good tends toward equality throughout the area. However, for certain goods the transportation costs represent a significant part of their value, as, for example, in the case of natural gas. Thus, it is not possible for the same price to prevail throughout the territory. Building on that caveat, Marshall (1890) enriches the definition by adding: “ (...) but of course if the market is large, allowance must be made for the expense of delivering the goods to different purchasers; each of whom must be supposed to pay in addition to the market price a special charge on account of delivery." So, this definition allows the local price at two distinct locations to differ, provided the spatial price spread equals the intermarket transportation cost. This equality is usually termed the "Law Of One Price" (LOOP) in the literature. This definition (and thus the LOOP) recurrently serves as a canonical reference to determine whether two geographically-distinct markets are integrated or not.

However, from an empirical perspective, the operationalization of Marshall's definition in the context of natural gas markets raises a number of concerns. First, the physical cost to move natural gas from a location $A$ to a location $B$ is not necessarily equal to the cost incurred when moving it from B to A. As we shall clarify below, this remark calls for a direction-specific approach that can be particularly important in the context of gas markets connected by bidirectional pipeline infrastructures. Second, even if the direction of trade is time-invariant, the transportation cost of moving the gas from an exporting area to an importing one (e.g., the freight or pipeline cost) can be time-varying. Third, it can be that the transportation costs are not the same for all market players. There exists, for example, a secondary market for the pipeline capacity or an auction-based system of capacity allocation. As for transport by sea, there can be differences between spot freight rates and the long-term lease cost, and the cost of fuel could also vary depending on its price at the moment of refueling. Fourth, the transportation costs can represent only a fraction of the overall transfer costs (not necessarily observable) incurred by shippers. ${ }^{3}$

To overcome these issues, one might be tempted to follow Spiller and Huang (1986) who introduce the notion of arbitrage costs, saying that two spatially distinct areas belong to the same economic market if they are linked by binding arbitrage conditions, i.e., in response to a price increase at one point an arbitrage takes place provided the spatial price difference equals the arbitrage (transaction) costs. An

\footnotetext{
${ }^{2}$ In this paper, the discussion focuses on economic markets and thus is not concerned with the industrial organization debates related to the delineation of an antitrust market that emerged in the 1960s.

${ }^{3}$ Clark (1984) argues that instead of transportation costs we should refer to arbitrage (transaction) costs, which along with the shipment costs could include information and hedging costs and other costs related to the policy (quotas, taxes). In this paper we refer to the transportation costs in their large sense and assume that the terms transportation costs and arbitrage (transaction) costs can be used interchangeably.
} 
interesting insight revealed by their analysis is that, in the presence of local demand and supply shocks, two areas can be in the same economic market for some observations and not for others. Hence, the validity of the LOOP may be time-varying.

As the preceding approach emphasizes the role of rational arbitragers, one can be tempted to refer to the theoretical literature on spatial price determination by Enke (1951), Samuelson (1952), and Takayama and Judge (1971). ${ }^{4}$ According to this logic we can represent the arbitrage activity performed between two markets $j$ and $i$ at time $t$ by the following complementarity condition. Assuming perfect competition and denoting the intermarket marginal transfer cost from market $j$ to market $i$ by $T_{j i t}$, the equilibrium prices (labeled $P_{j t}$ and $P_{i t}$ ) and the equilibrium aggregate flow $Q_{j i t}$ are related as follows:

$$
0 \leq Q_{j i t}, \quad P_{i t}-P_{j t}-T_{j i t} \leq 0 \quad \text { and } \quad\left(P_{i t}-P_{j t}-T_{j i t}\right) Q_{j i t}=0
$$

The complementarity condition (1) ensures that there is no trade from market $j$ to market $i$ (i.e., $Q_{j i t}=0$ ) when the spatial price spread is less than the transfer cost. This situation corresponds to the case of spatially segmented markets. Otherwise, when the markets are linked through spatial arbitrage (i.e., $Q_{j i t}>0$ ) the price spread equals the intermarket transfer cost and thus the LOOP holds.

Based on spatial equilibrium theory, this mathematical definition of market integration emphasizes the time-varying nature of integration, accounts for direction-specific conditions of trade, points out that the trade is performed by economically rational arbitragers, and incorporates the role of arbitrage costs. However, it should be noted that the notion of equilibrium is larger than the notion of integration. The tradability of goods is a crucial element for determining the market integration. As follows from this complementarity condition (1), in some periods two markets can stay in a segmented equilibrium whereby prices differ by less than the intermarket transfer cost.

In sum, we notice that the notion of an integrated market comes from the general sense of an economic market and, after being formulated mathematically and investigated through the spatial equilibrium theory, it obtains micro foundations. Based on this analysis we can now formulate a thorough definition of an integrated market: on a spatially integrated market the spatial price difference equals the unit intermarket transportation costs. However, it is challenging to empirically verify whether the theoretical condition holds. Thus, the empirical literature proposes different methodologies to measure the degree of market integration. These methods are described in the next section.

\section{3 - Methodologies}

\section{1. - Classification}

\footnotetext{
${ }^{4}$ Building on a critique of Marshall's inappropriate treatment of space (Enke, 1942), Enke (1951) first examines the case where a number of profit-seeking agents trade a homogeneous good at interconnected competitive regional markets and uses an electrical circuit analogue to show how the equilibrium prices, quantities, and commodity movements can be determined. That pioneering contribution strongly stimulated the academic community: (i) Samuelson (1952) subsequently entirely reformulated Enke's analysis in economic terms by reformulating Enke's model as a net social pay-off maximization problem; (ii) Takayama and Judge $(1964,1971)$ showed how adopting the assumption of linear regional demand and supply relations makes it possible to formulate the problem as a quadratic optimization problem where first-order conditions boil down to the complementarity conditions presented in this paper.
} 
We now detail a tentative methodological clustering of the numerous empirical contributions aimed at assessing the degree of spatial integration between natural gas markets.

\section{A - Early correlation-based studies}

According to Stigler and Sherwin (1985), in integrated markets the price movements should be similar (that implicitly assumes the stationarity of transportation costs). Thus, the authors propose measuring simple bivariate price correlations as a generic method of delineating geographic markets and argue that the presence of a large and positive correlation indicates a high degree of price integration between two markets for a relatively homogeneous commodity. In case of non-stationary price data they suggest using first-differenced series to avoid spurious results (i.e., artificially high correlation coefficients). Following Stigler and Sherwin (1985), Doane and Spulber (1994) detail an application of that simple approach to examine the degree of spatial integration among the North American regional markets for natural gas.

\section{$B$ - Cointegration test}

Cointegration theory provides an appealing and popular approach to test for market integration between stochastically varying prices at geographically dispersed markets. Two non-stationary price series are cointegrated if they have a stationary linear combination. The presence of such a cointegrating equation suggests that the deviations of one price series from another (and thus the geographical spread between them) are limited by the existence of a long-run relation which can be interpreted as reflecting the effects of the arbitrage activities conducted between the marketplaces.

Unsurprisingly, a vast literature applies the bivariate cointegration approach to empirically explore whether or not the natural gas prices at various locations are linked by such a long-run relation. Following the two-step procedure developed by Engle and Granger (1987), the analyses presented in De Vany and Walls (1993, 1996), Doane and Spulber (1994), Walls (1994), Serletis (1997), and Serletis and Herbert (1999) document the level of spatial price integration within the North American region in the aftermath of restructuration reforms in the gas industry conducted in the 1980s and 1990s. The corresponding literature focusing on the relations between the Western European gas markets remains sparse (Asche et al., 2001; 2002; 2013; Renou-Maissant, 2012). From a methodological perspective, these studies opt for the multivariate cointegration test procedure proposed in Johansen (1991). In addition, the cointegration approach is also used to investigate the intercontinental interactions between prices observed in North America, Europe, and Asia (Siliverstovs et al., 2005) or between American and European prices (Brown and Yücel, 2009). It should be noted that, in contrast to North American studies, some analyses conducted for the European or the intercontinental gas markets include the oil price in the list of regressors to model the effects of the oil-indexed pricing clauses stipulated in long-term contracts for natural gas.

An important limitation of the cointegration method is that it implicitly posits the existence of a stable and time-invariant long-run relationship between the price series. However, evidence gained from the restructuring reforms implemented in the natural gas industry suggests that the institutional changes have a gradual nature which could question the stability of the long-run coefficients.

\section{C - Granger causality/VAR/VECM}

According to the definition of causality posited by Granger, a variable X "causes" another variable $Y$ when the prediction of the current value of $\mathrm{Y}$ can be improved by incorporating information on the past 
values of X. Building on that approach, a number of contributions examine the short-run behavior of the price series and test for the presence of Granger causality (e.g., Doane and Spulber, 1994; Serletis and Herbert, 1999; Brown and Yücel, 2008) to analyze the predictability of prices, transmission of shocks, and detect eventual constraints on arbitrage.

Natural gas is a network industry which suggests that the transportation path between two markets may not be unique. Building on this observation, De Vany and Walls (1996) adopt a multivariate perspective and specify a vector auto-regression (VAR) model where the first-differenced price in each node depends on the lagged values of the price differences in all nodes. They analyze impulse response functions to study the shock transmission. An extension of the VAR framework is proposed in Nick and Thoenes (2014) who specify a structural VAR to examine the endogeneity of fundamental gas market variables, such as storage and LNG supplies.

To account for the possible existence of long-term and short-term relations between gas price series, Bachmeier and Griffin (2006), Park et al. (2008), Brown and Yücel (2008, 2009), Schultz and Swieringa (2013), Olsen et al. (2015) and Growitsch et al. (2015) estimate a vector error-correction model (VECM). This approach distinguishes the long-term cointegrating relationship between the prices and the shortterm deviations from it. Some studies, such as Mohammadi (2011), propose an extended specification allowing either the possibility of structural breaks in cointegration relationships or the possibility of asymmetric adjustments toward equilibrium. Others (e.g., Park et al., 2008; Olsen et al., 2015) use the variance/covariance matrix of the error term of a VAR/VECM to determine directed acyclic graphs aimed at explaining the contemporaneous transmission of price shocks between markets.

The autoregressive and error correction specifications provide useful conclusions about the price interrelations, but bring us away from the theoretical notion of integration, as the role played by transportation costs is de facto overlooked in these specifications.

$$
\text { D - Kalman filter }
$$

As the implementation of the liberalization reforms can be described as a gradual process, it can be useful to examine the evolution of the local prices to determine whether some form of convergence is observed over time. In a pioneering contribution focusing on the North American spot markets, King and Cuc (1996) argue that prices should converge over time to a state where their difference equals the transportation costs, and propose a dynamic, time-varying-parameter model to investigate it. This statespace model is estimated using a specific optimization algorithm: the Kalman Filter. The authors examine the price convergence between a market pair and assume that the price of the good in one market can be expressed as a linear function of the price in the other market with two coefficients: (i) a time-varying slope which is interpreted as an indicator of the strength of the pricing relationship, and (ii) an intercept coefficient capturing transaction costs between the markets. The LOOP holds if the slope coefficient at any time $t$ is equal to one whereas if that coefficient is constant and equal to 0 no relationship between the prices exists. Their findings document a strengthening price convergence over time but not homogeneously distributed within the US.

A growing literature is applying the state-space modeling strategy: (i) to examine the convergence of European prices (Neumann et al., 2006; Renou-Maissant, 2012; Neumann and Cullmann, 2012); or (ii) to study the effects of intercontinental arbitrage on prices either in the Atlantic Basin (Neumann, 2009) or 
the imperfect and seasonal convergence of LNG price indices in East Asia, Iberia, Northwest Europe, and South America (Mu and Ye, 2018). In addition, Growitsch et al. (2015) offer an interesting extension to the original model by specifying a state-space model for German and Dutch prices that includes a timevarying error correction component.

However, Li et al. (2014) note that this approach relies on a bivariate formulation of the LOOP. Therefore, when the market integration question involves the interaction of more than two prices, this method only reveals a part of the full picture.

\section{E - Price convergence estimations}

Li et al. (2014) propose a multivariate approach to explore the relationships between North American, European, and Asian natural gas markets. Their analysis is based on Phillips and Sul (2007) who provide a statistical test aimed at detecting convergence among a group of prices and an algorithm for the identification of subgroups in the case where some series are not converging within a core group. The authors conclude with the convergence of Asian and European prices, but not with the North American market. A recent application of this methodology is also presented in Mu and Ye (2018) who examine the integration of spot LNG markets and report on a higher convergence following the Fukushima accident.

\section{$F-A R$ models of price spreads}

Cuddington and Wang (2006) focus on the spreads between gas prices at different locations in the US and verify the stationarity of pairwise price differentials. Following Taylor (2001, p. 474), they argue that "if the price series at geographically dispersed locations are I(1) processes, then there is an equilibrium or stationary price gap between these two locations, if and only if they are within an integrated or unified market." Therefore, for any price spread where the unit root hypothesis is statistically rejected, they estimate an autoregressive model for the price gap to analyze the speed of adjustment toward the equilibrium price spread. They find that the eastern and central US regions are more integrated than the Western market.

\section{$G$ - Other models}

This category gathers the contributions that are not based on the standard tools used in time-series econometrics.

Kleit (1998) examines the arbitrage conducted between two markets and focuses on the role played by the arbitrage costs using a switching regime approach derived from the seminal work of Spiller and Huang (1986). His analysis draws on the market equilibrium notion as it de facto recognizes that there can exist autarky periods during which the price spread is lower than the arbitrage costs and periods during which the price spread equals the arbitrage cost.

Micola and Bunn (2007) empirically study the degree of spatial integration between the UK and Belgian markets when these two markets were linked by a unique pipeline infrastructure. A notable aspect of their contribution is the inclusion of a non-price variable: the capacity utilization ratio of the pipeline infrastructure. Their findings call for further attention to be paid to the interactions between the infrastructure use and the spatial price spread as they show that above a certain capacity utilization rate, 
the two local markets split. In that vein, an emerging literature is now capturing the effect of infrastructure issues on spatial price formation. ${ }^{5}$

\section{2. - Remarks}

Some insights can be derived from that classification. First, most empirical methodologies estimate the relation between the prices. The methods in categories $\mathrm{A}, \mathrm{B}$, and $\mathrm{C}$ emphasize the existence of common price movements that are either contemporaneous or lagged. The methods in B, F, and the VECM listed in category $\mathrm{C}$ test for the presence of stable long-term relations between the price series. The existence of convergence patterns is a central feature of the methods mentioned in D and E, while the methods in $G$ focus on the relations between the spatial price spread and the intermarket transportation cost.

Second, we observe that the literature is heavily dominated by the application of time-series techniques as a vast majority of studies focus on the time-series properties of the prices. These works investigate the convergence of prices and/or how price shocks are transmitted among the markets. By that, one can be tempted to highlight an intellectual connection with Cournot's definition of an integrated market that emphasizes the dynamics of the price convergence. However, with few exceptions (e.g., Cuddington and Wang, 2006; Kleit, 1998) the analysis is performed without an explicit reference to a microeconomic background and can thus be perceived as atheoretical.

Third, we note that only a handful of contributions consider the role of non-price variables in the analysis and study the effects of transaction costs, trade flows, and capacity constraints on market integration.

Lastly, it is important to keep in mind: (i) that each method has its limitations that can affect the conclusions about the observed degree of market integration; and (ii) that the application of different methodologies to a given set of markets can bring different (and sometimes opposite) results (e.g., King and Cuc, 1996; Serletis, 1997; Cuddington and Wang, 2006; Olsen et al., 2015). We also observe a tendency in the literature to apply different methodologies and compare the various results in order to overcome that problem.

\section{4 - Discussion}

\section{1. - Examples of extensions for considered methodologies}

Analyzing the literature on the integration of gas markets reviewed above, one can identify a series of either neglected or overlooked issues that could motivate future extensions.

\section{A - The role of local price elasticities of supply and demand}

A number of econometric works focus on price movements and their reactions to different shocks or study the shock transmission among the local markets. However, such approaches could underestimate the degree of integration of the markets with different supply and demand elasticities (Werden and Froeb, 1993), since the price reactions to a demand shock in one market and the supply response in another may

\footnotetext{
${ }^{5}$ For instance, Kuper and Mulder (2016) assess the impacts of both the infrastructure utilization and the institutional changes on cross-border price differences; Avalos et al. (2016) document the short-run price effects of capacity expansions in Florida; and Massol and Banal-Estañol (2016) also explicitly account for capacity constraints.
} 
not have the same amplitude. Thus, these approaches convey the risk to show that markets are not integrated on the grounds that prices do not experience the same movements.

\section{$B$ - The underlying role of oil prices}

The oil and gas markets have long been reputed to be linked both on the supply and on the demand side. Oil-indexed pricing formulas are still present in long-term gas and LNG contracts. However, today's market observers regularly claim that there is a declining use of the traditional oil-indexed clauses in favor of market-based pricing rules. Yet, the exact role played by oil prices deserves further investigations as the literature disagrees on that topic. ${ }^{6}$

If one supposes that natural gas trade is infinitely costly between two locations but the natural gas prices at these two markets are synchronously affected by the price of oil then, under such a situation, one has to be certain that the empirical methodology retained to assess the degree of spatial integration between these two gas markets will not fail to conclude that they are segmented. This remark calls for further attention to be paid to underlying role of oil prices.

\section{$C$ - The role of transfer cost}

Only a few existing studies explicitly consider the role of transportation and arbitrage costs. In the gas industry these costs can take a significant value, up to $50 \%$ of the price. ${ }^{7}$ Thus, one can hardly disregard their role in the formation of natural gas prices (and thus of spatial price spreads), even if their estimation is not straightforward (Olsen et al., 2015). Two notable exceptions are: (i) Kleit (1998) who uses the geographical price spreads to estimate the arbitrage costs; and (ii) Growitsch et al. (2015) who subtract transmission charges from the spatial price differences. However, the arbitrage cost incurred by traders may be larger than the infrastructure cost: unobserved transaction costs or risk premiums can also affect the traders' decisions (especially for long-haul LNG trade). Moreover, it should be noted that this cost can vary with the direction of the trade flows. For market pairs with a possibly changing direction over time (e.g., between the UK and Belgium), trade direction is an information that can hardly be overlooked in empirical studies. ${ }^{8}$

\section{$D$ - The role of trade flows}

The discussion in Barrett and $\mathrm{Li}$ (2002) is devoted to the role of trade flows between two markets and can be used to verify whether the markets are linked by effective trade (as in the case of a positive trade flow) or by contestability arguments (in case of zero intermarket trade). In the latter case, the price spread can still equal the intermarket transfer cost if the traders are indifferent to trade or not. Building on that logic, the possibly distinct roles of commercial and physical flows could be further explored. For the studies focusing on pipeline-linked market pairs, it could provide useful insights into how the procedures for the allocation of transportation rights influence the observed degree of market integration.

\footnotetext{
${ }^{6}$ Indeed, a series of studies show that the oil price still plays an important role, being the main driver of the gas market (Bachmeier and Griffin, 2006; Hartley et al., 2008; Brown and Yücel, 2009; Asche et al., 2013) whereas other authors (Neumann, 2009; Hulshof et al., 2016; Mu and Ye, 2018) argue that the gas prices are now determined by their own fundamentals.

${ }^{7}$ Sources: Platts LNG Daily (November, 2016), EIA: https://www.eia.gov/dnav/ng/hist/rngwhhdD.htm.

${ }^{8}$ To our knowledge, a notable example is given by Neumann et al. (2006) who present one of the few regressionbased studies incorporating direction-specific dummy variables.
} 


\section{E- Capacity constraints}

Capacity constraints are evoked in a number of empirical studies based solely on prices series (e.g., De Vany and Walls, 1993, 1996; King and Cuc, 1996; Brown and Yücel, 2008). However, capacity utilization is a time-varying variable and the scope of market integration is likely to be time-varying, too. In case of a congested infrastructure, we should observe larger than usual spatial price spreads and decoupled markets. In contrast, the observation of a large price difference between two markets connected by an infrastructure exhibiting spare capacity indicates the presence of unexploited arbitrage opportunities. Surprisingly, the attention paid to capacity constraints while assessing the level of market integration is very recent in the empirical literature (e.g., Kuper and Mulder, 2016; Avalos et al., 2016; Massol and Banal-Estañol, 2016).

\section{F - Imperfect competition}

By construction, Marshall's definition of an integrated market presumes the existence of competitive spatial arbitrage. It is important to keep in mind that noncompetitive behavior of arbitragers could influence the intermarket price spread ${ }^{9}$ and make it deviate from the value of transaction costs. A situation with abnormally high price spreads may indicate the presence of unexploited arbitrage opportunities which can be explained by imperfect competition. Unfortunately, most of the discussed empirical methodologies are unable to deal with this issue. However, a few studies provide a set-up (either based on regression techniques or spatial equilibrium theory) that enables us to detect the presence of market power (e.g., Micola and Bunn, 2007; Massol and Banal-Estañol, 2016).

\section{2. - The extended conditions for spatial equilibrium}

Based on the analysis above, we can show how some of the proposed extensions could be directly reflected in the mathematical formulation of market integration, presented in this paper. Indeed, the EnkeSamuelson-Takayama-Judge condition for spatial equilibrium can be modified in order to account for the distinct features of natural gas transportation infrastructures.

While presented in the second section the complementarity condition (1) allows us to explicitly consider direction-specific transfer costs and trade flows, its extended version takes into account eventual capacity constraints. Ceteris paribus, assuming that the physical trade takes place through a transportation infrastructure that has a finite transportation capacity $K_{j i t}$ the arbitrage activity performed between two markets $j$ and $i$ at time $t$ can be characterized by the following complementarity conditions:

$$
\begin{aligned}
& 0 \leq Q_{j i t}, \quad P_{i t}-P_{j t}-T_{j i t}-\xi_{j i t} \leq 0 \quad \text { and } \quad\left(P_{i t}-P_{j t}-T_{j i t}-\xi_{j i t}\right) Q_{j i t}=0 \text {, } \\
& 0 \leq \xi_{j i t}, \quad Q_{j i t} \leq K_{j i t} \quad \text { and } \quad\left(Q_{j i t}-K_{j i t}\right) \xi_{j i t}=0 \text {, }
\end{aligned}
$$

where $\xi_{j i t}$ is the marginal congestion cost to use the infrastructure. The complementarity condition (3) ensures that the marginal congestion cost $\xi_{j i t}$ is equal to zero whenever the transportation capacity constraint $Q_{j i t} \leq K_{j i t}$ is slack, and $\xi_{j i t}$ is positive when this constraint is binding. In case of a zero

\footnotetext{
${ }^{9}$ For example, withholding transportation capacity will raise the price spread.
} 
marginal congestion cost (i.e., $\xi_{j i t}=0$ ), the complementarity condition (2) ensures that (i) there is no trade activity between the two markets (i.e., $Q_{j i t}=0$ ) when the spatial price spread is less than the transaction cost and (ii) the price spread equals the transfer cost (i.e., the markets are integrated) when trade occurs and it is not constrained by the infrastructure's capacity (i.e., $0<Q_{j i t}<K_{j i t}$ ). In case of a binding capacity constraint (i.e., $Q_{j i t}=K_{j i t}$ and $\xi_{j i t}>0$ ), the difference between the spatial price spread and the transfer cost is positive (i.e., $\left.P_{i t}-P_{j t}-T_{j i t}>0\right)$ and the associated scarcity rent $\left(P_{i t}-P_{j t}-\right.$ $\left.T_{j i t}\right) K_{j i t}$ accrues to the agents that are trading using the congested infrastructure.

These two complementarity conditions represent three spatial equilibrium states: (i) an autarchic equilibrium (when the spatial price spread is less than the transaction cost), (ii) an integrated equilibrium (when the spread equals the transaction cost) and (iii) a congestion one (with the price spread exceeding the transaction cost). Thus, accounting for these three distinct regimes could provide interesting insights into the relations between two markets places.

\section{5 - Conclusion}

The research interest in the integration of natural gas markets has been supported by the rapid emergence of wholesale markets for natural gas and their structural changes. Numerous regulatory reforms aimed at a liberalized and integrated gas market have been implemented in the main gas-consuming regions worldwide. Sometimes the adaptation to the new conditions encounters some difficulties. Existing pipeline congestions, insufficient coordination between traders and transmission operators, lack of transparency in the market, lack or asymmetry of information, distrust of the spot market or little experience of dealing with it and, by consequence, low liquidity - all of that needs to be overcome on the way to an integrated market. Fortunately, enabled spatial arbitrage is enforcing the link between gas markets, making them more integrated.

The analysis of the prolific empirical literature regarding spatial integration gives us some insights into price formation and allows a better understanding of the relation between the gas prices in different locations. The theoretical definition of an integrated market suggests that the prices in diverse locations differ on the value of intermarket transportation costs. This simple definition is challenging to verify empirically. Numerous studies attempt to estimate the integration of the gas markets using different approaches. Their conclusions are mixed and sometimes the use of different methodologies to a given set of markets can bring different results. However, a lot of studies report on an increase in the time degree of integration of regional markets with liberalization reforms playing an important role in this process. Even if there are well-integrated regions with relatively developed interconnected grids, like the North American or to a lesser extent European markets, it is too early to speak about a unique integrated world gas market.

In recent years, the methodologies used to assess the degree of geographical market integration have evolved and became more complex. Progressing from a static to a dynamic perspective, with an extended spatial scope of analysis, the assessment of the market integration still has the potential to be further investigated.

Most empirical studies focus on the price integration between spatially different markets, assessing the correlation, cointegration, Granger causality, autoregressive, error correction, price convergence or time- 
varying coefficients models, relying solely on price data. A close examination of the literature reveals that only a handful of studies account for the role played by trade flows, capacity constraints, and unit transaction costs. However, these issues provide important information for the conclusion of whether two markets are segmented or integrated. In this light, it seems legitimate to call for further attention to be paid to the theoretical conditions for spatial market equilibrium. Notwithstanding the fact that the verification of these conditions in real life is known to be challenging, the topic of the spatial integration of gas markets, supported by the policy objective to create an integrated energy market, is likely to attract the attention of researchers in the future.

\section{References}

Papers of particular interest, published recently, have been highlighted as:

* Of importance

** Of major importance

ACER. European Gas Target Model review and update. January 2015.

Asche F, Misund B, Sikveland M. The relationship between spot and contract gas prices in Europe. Energy Economics. 2013:38: 212-217.

Asche F, Osmundsen P, Tveterås R. Market integration for natural gas in Europe. International Journal of Global Energy Issues. 2001:16: 300-312.

Asche F, Osmundsen P, Tveterås R. European Market Integration for Gas? Volume Flexibility and Political Risk. Energy Economics. 2002:24(3): 249-265.

Avalos R, Fitzgerald T, Rucker RR. Measuring the effects of natural gas pipeline constraints on regional pricing and market integration. Energy Economics. 2016:60: 217-231.

Bachmeier LJ, Griffin JM. Testing for market integration, crude oil. Coal and natural gas. Energy Journal. 2006:27: 55-72.

Barrett CB, Li JR. Distinguishing between Equilibrium and Integration in Spatial Price Analysis. American Journal of Agricultural Economics, 2002:84(2): 292-307.

Brown SPA, Yücel MK. Deliverability and regional pricing in U.S. natural gas markets. Energy Economics. 2008:30(5): 2441-2453.

Brown SPA, Yücel MK. Market arbitrage: European and North American natural gas prices. The Energy Journal Special Issue. 2009:167-185. https://doi.org/10.5547/issn0195-6574-ej-vol30-nosi-11.

Clark TA. Violations of the Gold Points, 1980-1908. Journal of Political Economy. 1984:92(5): 791-823.

Cournot A.-A. Recherches sur les Principes Mathématiques de la Théorie des Richesses. 1838. Paris. 
Cuddington JT, Wang Z. Assessing the degree of spot market integration for US natural gas: evidence from daily price data. Journal of Regulatory Economics 2006:29(2): 195-210.

De Vany A, Walls WD. Pipeline Access and Market Integration in the Natural Gas Industry: Evidence from Cointegration Tests. The Energy Journal 1993:14(4): 1-19.

De Vany A, Walls WD. The law of one price in a network: Arbitrage and Price Dynamics in Natural Gas City Gate Markets. Journal of Regional Science. 1996:36(4): 555-570.

Doane MJ, Spulber DF. Open Access and the Evolution of the U. S. Spot Market for Natural Gas. Journal of Law and Economics. 1994:37(2): 477-517.

Engle RF, Granger CW. Cointegration and Error Correction: Representation, Estimation and Testing. Econometrica. 1987:55: 251-276.

Enke S. Space and Value. The Quarterly Journal of Economics, 1942:56(4): 627-637.

Enke S. Equilibrium among Spatially Separated Markets: Solution by Electric Analogue. Econometrica. 1951:19(1): 40-47.

European Commission. Energy Union package. February 2015.

European Parliament. Energy Union: Key Decisions for the Realisation of a Fully Integrated Energy Market. April, 2016.

* Growitsch Ch, Stronzik M, Nepal R. Price Convergence and Information Efficiency in German Natural Gas Markets. German Economic Review. 2015:16(1): 87-103. The paper covers different methodologies of assessment of the market integration and attempts to account for transportation costs.

Hartley P, Medlock K, Rosthal J. The Relationship of Natural Gas to Oil Prices. The Energy Journal. 2008:29(3): 47-66.

Hulshof D, Mulder M, Van Der Maat J-P. Market Fundamentals, Competition and Natural Gas Prices. Energy Policy. 2016:94: 480-491.

IGU World LNG report - 2015 Edition I.

Johansen S. Estimation and hypothesis testing of cointegration vectors in Gaussian autoregressive models. Econometrica. 1991:59: 1551-1580.

King M, Cuc M. Price Convergence in North American Natural Gas Spot Markets. The Energy Journal 1996:17(2): 17-42.

Kleit AN. Did Open Access integrate Natural Gas Markets? An Arbitrage Cost Approach. Journal of Regulatory Economics. 1998:14(2): 19-33.

Kuper G, Mulder M. Cross-border constraints, institutional changes and integration of the Dutch-German gas market. Energy Economics. 2016:53: 182-192. 
* Li R, Joyeux R, Ripple RD. International natural gas market integration. The Energy Journal. 2014:35(4): 159-179. The paper employs recent methodologies based on price convergence and assesses the degree of market integration between different regions using pipeline and LNG prices.

Marshall A. Principles of economics. Book Five: General Relations of Demand, Supply and Value. Chapter 1. 1890.

** Massol O, Banal-Estañol A. Market power and spatial arbitrage between interconnected gas hubs. USAEE Working Paper No. 16-281. 2016. The paper applies a new approach based on spatial equilibrium theory and accounts for transportation costs, trade flows and capacity constraints.

Micola AR, Bunn DW. Two markets and a weak link. Energy Economics. 2007:29:79-93.

Mohammadi H. Market integration and price transmission in the U.S. natural gas market: from the wellhead to end use markets. Energy Economics. 2011:33: 227-236.

$\mathrm{Mu} \mathrm{X}, \mathrm{Ye} \mathrm{H}$. Towards an Integrated Spot LNG Market: An Interim Assessment. The Energy Journal. 2018:39(1).

Neumann A. Linking Natural Gas Markets - Is LNG Doing its Job? Energy Journal. Special Issue. 2009:30: 187-199.

Neumann A, Cullmann A. What's the story with natural gas markets in Europe? Empirical evidence from spot trade data. 9th International Conference on the European Energy Market. 2012.

Neumann A, Siliverstovs B, von Hirschhausen C. Convergence of European spot market prices for natural gas? A real-time analysis of market integration using the Kalman Filter. Applied Economics Letters. 2006:13(11): 727-732.

Nick S, Thoenes S. What drives natural gas prices?-A structural VAR approach. Energy Economics. 2014:45, 517-527.

* Olsen KK, Mjelde JW, Bessler DA. Price formulation and the law of one price in internationally linked markets: an examination of the natural gas markets in the USA and Canada. The Annals of Regional Science. 2015:54(1) 117-142. In addition to VECM estimation the paper performs directed acyclic graph and variance decomposition analyses.

Park H, Mjelde JW, Bessler DA. Price interactions and discovery among natural gas spot markets in North America. Energy Policy 2008:36(1): 290-302.

Phillips PCB, Sul D. Transition modelling and econometric convergence tests. Econometrica. 2007:75:1771-1855.

Platts LNG Daily, November, 2016.

https://www.platts.com/IM.Platts.Content/ProductsServices/Products/lngdaily.pdf

Renou-Maissant P. Toward the Integration of European Natural Gas Markets: A timevarying Approach. Energy Policy. 2012:51: 779-790. 
Samuelson PA. Spatial Price Equilibrium and Linear Programming. The American Economic Review. 1952:42(3): 283-303.

Schultz E, Swieringa J. Price discovery in European natural gas markets. Energy Policy. 2013:61: 628634.

Serletis A. Is There an East-West Split in North American Natural Gas Markets? The Energy Journal. 1997:18(1): 47-62.

Serletis A, Herbert J. The message in North American energy prices. Energy Economics. 1999:21: 471483.

Siliverstovs B, L'Hégaret G, Neumann A, von Hirschhausen, C. International market integration for natural gas? A cointegration analysis of prices in Europe, North America and Japan. Energy Economics. 2005:27(4): 603-615.

Spiller PT, Huang CJ. On the Extent of the Market: Wholesale Gasoline in the Northern United States. Journal of Industrial Economics. 1986:35(2): 131-145.

Stigler GJ, Sherwin RA. The Extent of the Market. Journal of Law and Economics. 1985:28(3): 555-585.

Takayama T, Judge GC. Equilibrium among Spatially Separated Markets: A Reformulation. Econometrica. 1964:32(4): 510-524.

Takayama T, Judge GC. Spatial and Temporal Price and Allocation Models. North- Holland: Amsterdam. 1971.

Taylor AM. Potential pitfalls for the purchasing-power-parity puzzle? Sampling and specification biases in mean-reversion tests of the law of one price. Econometrica, 20016:9(2): 473-498.

Walls D. Price Convergence across Natural Gas Fields and City Markets. The Energy Journal. 1994:15(4): 37-48.

Werden GJ, Froeb LM. Correlation, Causality, and All that Jazz: The Inherent Shortcomings of Price Tests for Antitrust Market Delineation. Review of Industrial Organization. 1993:8(3): 329-354. 